CLINICAL STUDY

\title{
Intraepidermal nerve fiber density reduction as a marker of preclinical asymptomatic small-fiber sensory neuropathy in hypothyroid patients
}

Flavia Magri, Michelangelo Buonocore ${ }^{1}$, Antonio Oliviero ${ }^{2}$, Mario Rotondi, Anna Gatti ${ }^{1}$, Silvia Accornero, Antonella Camera and Luca Chiovato

Unit of Internal Medicine and Endocrinology, Fondazione Salvatore Maugeri I.R.C.C.S., University of Pavia, Via S. Maugeri 10, I-27100 Pavia, Italy,

${ }^{1}$ Unit of Clinical Neurophysiology and Neurodiagnostic Skin Biopsy, Fondazione Salvatore Maugeri I.R.C.C.S., I-2710O Pavia, Italy and ${ }^{2}$ FENNSI Group, Hospital Nacional de Parapléjicos, SESCAM, 45071 Toledo, Spain

(Correspondence should be addressed to L Chiovato; Email: luca.chiovato@fsm.it)

\begin{abstract}
Aim: To evaluate, by using skin biopsy technique, the intraepidermal nerve fiber (IENF) density in a group of untreated patients with hypothyroidism, either overt $(\mathrm{OH})$ or subclinical $(\mathrm{SH})$, who did not complain of neurologic symptoms.

Methods: We evaluated 18 neurologically asymptomatic patients newly diagnosed with $\mathrm{OH}$ or SH. Fifteen healthy, age-matched, controls were also studied. A nerve conduction study was performed. Skin biopsy was carried out from the skin of upper thigh and distal leg. Nerve fiber density was measured using an immunofluorescence technique. The density of innervation was calculated by counting only fibers crossing the basement membrane.

Results: Electroneurographic parameters were similar in patients and controls. When compared with healthy controls, patients with $\mathrm{OH}$ or $\mathrm{SH}$ showed a significantly lower IENF density. As assessed by the proximal/distal fiber density ratio, the hypothyroid neuropathy was length dependent. When individually considered, an abnormally reduced IENF was observed in $60 \%$ of patients with $\mathrm{OH}$ at the distal leg and in $20 \%$ at the proximal site. In patients with SH, an abnormal IENF density was found at the distal leg in $25 \%$ of cases and at the proximal thigh in $12.5 \%$ of cases.

Conclusions: Our study provides the first direct demonstration of reduced IENF density in patients with $\mathrm{OH}$ or SH. In all patients, the IENF density reduction was length dependent. These findings suggest that a considerable number of untreated hypothyroid patients may have preclinical asymptomatic smallfiber sensory neuropathy.
\end{abstract}

European Journal of Endocrinology $163279-284$

\section{Introduction}

Neurologic complications, including polyneuropathy, are well-known findings in overt hypothyroidism $(\mathrm{OH})$, with a prevalence ranging from 42 to $72 \%(1,2)$. In neurologic series, the prevalence of hypothyroidism as a cause of polyneuropathy is reported to be around $2-4 \%$ $(3,4)$. Alterations in peripheral nerves are well documented in myxedema (2), but few data are available in subclinical hypothyroidism (SH) (5).

In the past, patients with long-standing, untreated hypothyroidism commonly complained of symptoms suggesting small-fiber sensory neuropathy (SFSN), such as paresthesies and burning extremity pain (6). Hypothyroid patients also experienced a sensorymotor polyneuropathy with a distal-proximal progression, first involving lower limbs and then the upper ones (7). It is generally accepted that the severity of the peripheral nervous system involvement is significantly related to the duration of hypothyroidism rather than to the degree of thyroid failure $(1,7)$. Thus, long-standing biochemical abnormalities might lead to neurologic alterations even in SH. Recently, painful neuropathy was reported in a patient with $\mathrm{SH}$ who recovered after hormone replacement therapy (8).

Skin biopsy is a safe and validated technique to assess intraepidermal nerve fiber (IENF) density. IENF density is a reproducible marker of SFSN, showing a sensitivity of more than $90 \%$ in the diagnosis of this type of sensory neuropathy $(9,10)$.

The aim of the current study was to evaluate the IENF density in a group of untreated patients with hypothyroidism, either $\mathrm{OH}$ or $\mathrm{SH}$, who did not complain of neurologic symptoms. Our data indicate that a reduction of IENF density, suggestive of SFSN, is a relatively common finding in $\mathrm{OH}$, but it is also detected in subclinical thyroid failure. 


\section{Materials and methods}

The study enrolled 18 patients (mean age 51.2 \pm 13.1 years) newly diagnosed with hypothyroidism. Ten patients presented with $\mathrm{OH}$, defined as raised serum levels of TSH associated with free thyroxine $\left(\mathrm{FT}_{4}\right)$ values below the normal range. Eight patients were classified as having SH because their serum levels of TSH were high $(>4 \mathrm{mIU} / \mathrm{l})$, while $\mathrm{FT}_{4}$ concentrations were in the normal range.

All patients were neurologically asymptomatic, and did not display motor symptoms, alterations of pin prick, light touch, vibration, and joint position sensation. Tendon reflexes were also normal. Diabetes mellitus (according to the American Diabetes Association Diagnostic Criteria (11), neurologic disorders, alcoholism and/or the use of neurotoxic/neuroactive drugs, low levels of vitamin B12 and folic acid (mean values \pm s.D. $493 \pm 180 \mathrm{pg} / \mathrm{ml}$, normal range 191-663, and $6.14 \pm 3.2 \mathrm{ng} / \mathrm{ml}$, normal range 3.8-16 respectively), were mandatory exclusion criteria.

In the majority of patients (14/18), hypothyroidism was caused by autoimmune thyroiditis. Three patients suffered from post-ablative hypothyroidism resulting from radioiodine therapy or total thyroidectomy. In two patients, radioiodine therapy for Graves' disease had been performed 60 and 12 months before inclusion in the study. One patient was diagnosed with central hypothyroidism (Table 1). The duration of hypothyroidism, calculated as the time elapsed from the biochemical diagnosis or from the surgical or radiometabolic procedure not followed by hormonal substitution, ranged from 3 to 60 months (median 12 months). Fifteen age-matched $(53.3 \pm 17.3$ years) controls with no neurologic/systemic diseases and not taking nervous system interfering drugs were also studied.
A nerve conduction study was performed in hypothyroid patients and controls to evaluate the presence of subclinical large fiber polyneuropathy. Both patients and controls gave their informed consent to participate in the study, which was performed in accordance with the guidelines of the Declaration of Helsinki and with the Institution Ethics Committee on human sperimentation.

\section{Serum assay}

Serum concentrations of $\mathrm{FT}_{4}$ (normal range $8-19 \mathrm{pg} / \mathrm{ml}$ ) and TSH (third generation TSH assay; normal range $0.4-4 \mathrm{mIU} / \mathrm{l})$ were measured using immunochemiluminiscent assays by an automated analyser (Immulite 2000, DPC Cirrus, Los Angeles, CA, USA) employing commercial kits (Diagnostic Products Corporation, Los Angeles, CA, USA). Serum concentrations of anti-thyroglobulin antibody ( $\mathrm{Tg}-\mathrm{Ab}$; normal range $<60 \mathrm{U} / \mathrm{ml}$ ) and anti-thyroid peroxidase antibody (TPO-Ab; normal range $<60 \mathrm{U} / \mathrm{ml}$ ) were measured using immunochemiluminiscent assays employing commercial kits (Brahams, Hennigsdorf, Germany).

\section{Nerve conduction study}

Electrophysiological examination was performed bilaterally on lower limbs with constant monitoring of skin and room temperature. Skin temperature was maintained between 32 and $34^{\circ} \mathrm{C}$, and room temperature was maintained between 22 and $24^{\circ} \mathrm{C}$. Motor nerve conduction velocities of deep peroneal nerves were measured with standardized surface stimulating and recording techniques. Sensory nerve conduction velocities in superficial peroneal nerves were measured antidromically. Motor and sensory action potential amplitude (MAP and SAP) and distal latency (DL)

Table 1 Clinical and laboratory features of patients with overt or subclinical hypothyroid (overt hypothyroidism $(\mathrm{OH})$ and subclinical hypothyroidism $(\mathrm{SH})$ respectively).

\begin{tabular}{|c|c|c|c|c|c|c|c|}
\hline & Age & Sex & Cause of hypothyroidism & $\begin{array}{l}\text { TSH (mIU/l) } \\
(0.4-4)\end{array}$ & $\begin{array}{l}\mathbf{F T}_{4}(\mathrm{ng} / \mathrm{dl}) \\
(0.8-1.9)\end{array}$ & $\begin{array}{l}\text { Tg-Ab }(\mathrm{U} / \mathrm{ml}) \\
(<60)\end{array}$ & $\begin{array}{l}\text { TPO-Ab (U/ml) } \\
(<60)\end{array}$ \\
\hline $\mathrm{OH}$ & 50 & $\mathrm{~F}$ & Post-thyroidectomy for multinodular goiter & 40 & 0.3 & 10 & 10 \\
\hline $\mathrm{OH}$ & 54 & M & Hashimoto's thyroiditis & 164 & 0.3 & 15 & 10740 \\
\hline $\mathrm{OH}$ & 74 & $\mathrm{M}$ & Central hypothyroidism & 0.26 & 0.49 & 12.4 & 10 \\
\hline $\mathrm{OH}$ & 58 & $\mathrm{~F}$ & Hashimoto's thyroiditis & 169 & 0.3 & 10 & 4823 \\
\hline $\mathrm{OH}$ & 51 & $\mathrm{~F}$ & Hashimoto's thyroiditis & 152 & 0.6 & 64.8 & 10 \\
\hline $\mathrm{OH}$ & 63 & $\mathrm{~F}$ & Post-radioiodine therapy for Graves' disease & 40 & 0.33 & 12.2 & 10 \\
\hline $\mathrm{OH}$ & 79 & $\mathrm{~F}$ & Hashimoto's thyroiditis & 21.7 & 0.63 & 43.8 & 3167 \\
\hline $\mathrm{OH}$ & 30 & $\mathrm{~F}$ & Hashimoto's thyroiditis & 289 & 0.3 & 207 & 60 \\
\hline $\mathrm{OH}$ & 56 & M & Hashimoto's thyroiditis & 112 & 0.35 & 10 & 588 \\
\hline $\mathrm{SH}$ & 46 & $\mathrm{~F}$ & Hashimoto's thyroiditis & 8.44 & 0.83 & 74.4 & 77 \\
\hline $\mathrm{SH}$ & 45 & $\mathrm{~F}$ & Hashimoto's thyroiditis & 23 & 1 & 176.9 & 11470 \\
\hline $\mathrm{SH}$ & 45 & $\mathrm{~F}$ & Hashimoto's thyroiditis & 16.8 & 0.95 & 176.4 & 1004 \\
\hline $\mathrm{SH}$ & 31 & $\mathrm{~F}$ & Hashimoto's thyroiditis & 9.65 & 1.02 & 70 & 42 \\
\hline $\mathrm{SH}$ & 42 & $\mathrm{M}$ & Hashimoto's thyroiditis & 9.6 & 1.27 & 10 & 5748 \\
\hline $\mathrm{SH}$ & 52 & $\mathrm{M}$ & Hashimoto's thyroiditis & 45.2 & 1.01 & 9348 & 2188 \\
\hline $\mathrm{SH}$ & 56 & $\mathrm{~F}$ & Hashimoto's thyroiditis & 13.4 & 0.81 & 152 & 212 \\
\hline
\end{tabular}


of MAP were measured in the same nerves. All electrophysiological parameters (conduction velocity (CV), distal motor latency, and potential amplitude) were compared with reference values obtained in agematched controls. An electrophysiological diagnosis of polyneuropathy was made when $\mathrm{CV}$ and/or DL and/or potential amplitude were abnormal bilaterally.

\section{Skin biopsy}

Using a 3-mm punch tool, two skin biopsies were carried out from the skin of the upper thigh $(20 \mathrm{~cm}$ below the iliac spine) and distal leg $(10 \mathrm{~cm}$ proximal to lateral malleolus). We will refer to these procedures as proximal and distal skin biopsies. Biopsy specimens were immediately fixed in cold Zamboni's solution and cryoprotected in PBS. Specimens were then cut into 50- $\mu$ m sections using a freezing sliding microtome. Nerve fibers were identified by indirect immunofluorescence. The primary antibody was directed against PGP 9.5 (Biogenesis, Poole, UK; 1:1000), a non-specific neuronal marker, and then detected using a secondary antibody conjugated to the cyanine dye fluorophor $\mathrm{Cy} 3$ (Jackson Immuno Research, West Grove, PA, USA). In order to identify the basement membrane, another primary antibody was directed against type IV collagen (Chemicon International, Temecula, CA, USA) and detected using a secondary antibody conjugated to the cyanine dye fluorophor Cy 2 (Jackson Immuno Research). Sections were finally adhered to coverslips with agar and dehydrated via an alcohol gradient. At the end of the processing, they were cleared with methyl salicylate and mounted in Dibutyl Phtalate Xylene (DDK, Milan, Italy).

Using a fluorescence microscope system (magnification $40 \times$, Axioskop 40 FL, Zeiss, Gottingen, Germany), the nerve fiber density was calculated by counting only fibers crossing the basement membrane. The density of IENF was expressed as the number of IENF per millimeter of epidermis (IENF/mm) (12).

\section{Statistical analysis}

Data were expressed as mean \pm s.D. We also calculated the proximal/distal (P/D) fiber density ratio in controls and hypothyroid patients. Between-group comparisons were performed by Student's $t$-test for unpaired data for both proximal and distal skin biopsies. Furthermore, due to skewed distribution of the numbers of small fiber detected by immunohistochemistry, nonparametric Mann-Whitney $U$ test was also used, providing the same conclusions. To indicate how many s.D.s the number of small fiber were above or below the mean, we calculated the $Z$ scores for each subject. A significant $\mathrm{Z}$ score was set at \pm 2 .

\section{Results}

Using the conventional electroneurographic approach, the mean values of the parameters evaluated were not different in patients with hypothyroidism, both SH and $\mathrm{OH}$, and in controls (Table 2). When individually considered, only two patients with $\mathrm{OH}$ showed electrophysiological findings indicative of polyneuropathy. In both cases, a mild reduction of motor and sensory CV $(30-35 \mathrm{~m} / \mathrm{s})$ and a reduction of SAP amplitude were observed, suggesting a sensory-motor neuropathy.

The results of skin biopsy are summarized in Fig. 1. When compared with healthy controls, patients with $\mathrm{OH}$ or $\mathrm{SH}$ showed a significantly lower IENF density, both at the proximal (P) thigh and at the distal (D) leg. A representative visualization of nerve fibers by indirect immunofluorescence on skin biopsy specimens from overt (A), subclinical (B) hypothyroid patients, and healthy control $(C)$ is shown in Fig. 2. As assessed by the $\mathrm{P} / \mathrm{D}$ fiber density ratio, the neuropathy observed in our hypothyroid patients was length dependent.

When individually considered, eight patients showed an abnormally reduced IENF ( $Z$ scores $<2)$. In particular, six out of ten patients $(60 \%)$ with $\mathrm{OH}$ and two out of eight $(25 \%)$ patients with $\mathrm{SH}$ had a reduced IENF density. Among patients with $\mathrm{OH}$, six $(60 \%)$ showed a reduction in the IENF at the distal leg and two $(20 \%)$ also at the proximal thigh. In patients with $\mathrm{SH}$, an abnormal IENF density was found at the distal leg in two cases $(25 \%)$ and also at the proximal thigh in one case $(12.5 \%)$. Z scores of proximal and distal IENF/mm in both groups of patients are reported in Fig. 3 .

When individually considered, the P/D fiber density ratio indicated a length-dependent neuropathy $(\mathrm{Z}$ scores $>2$ ) in four $(40 \%)$ patients with $\mathrm{OH}$ and in two

Table 2 Electroneurographic data of hypothyroid patients and control subjects (mean \pm S.D).

\begin{tabular}{|c|c|c|c|}
\hline & Controls & $\begin{array}{l}\text { Subclinical } \\
\text { hypothyroidism }\end{array}$ & $\begin{array}{c}\text { Overt } \\
\text { hypothyroidism }\end{array}$ \\
\hline Conduction velocity of left external sciatical popliteal nerve (m/s) & $46.61 \pm 2.72$ & $47.51 \pm 4.62$ & $45.85 \pm 4.73$ \\
\hline Conduction velocity of right external sciatical popliteal nerve (m/s) & $46.46 \pm 2.21$ & $47.09 \pm 3.02$ & $46.39 \pm 5.39$ \\
\hline Conduction velocity of left superior peroneal nerve $(\mathrm{m} / \mathrm{s})$ & $39.13 \pm 3.14$ & $39.28 \pm 4.98$ & $36.65 \pm 3.98$ \\
\hline Conduction velocity of right superior peroneal nerve $(\mathrm{m} / \mathrm{s})$ & $38.84 \pm 2.55$ & $38.71 \pm 4.11$ & $37.05 \pm 5.34$ \\
\hline Amplitude of left external sciatical popliteal nerve (mV) & $13.72 \pm 13.6$ & $9.41 \pm 4.34$ & $10.44 \pm 3.57$ \\
\hline Amplitude of right external sciatical popliteal nerve (mV) & $8.31 \pm 1.98$ & $9.53 \pm 3.97$ & $11.29 \pm 4.16$ \\
\hline Amplitude left superior peroneal nerve (mV) & $15.24 \pm 8.27$ & $19.19 \pm 10.4$ & $11.84 \pm 7.51$ \\
\hline Amplitude right superior peroneal nerve $(\mathrm{mV})$ & $14.35 \pm 8.43$ & $17.89 \pm 9.61$ & $13.28 \pm 8.72$ \\
\hline
\end{tabular}



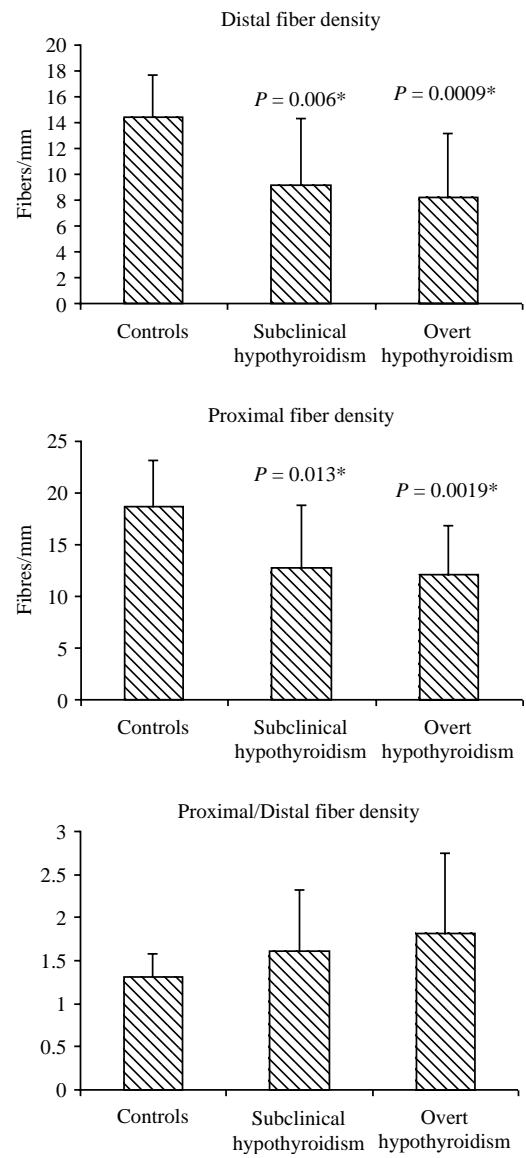

Figure 1 Intraepidermal nerve fiber density (means \pm S.D.; * versus Controls).

(25\%) patients with SH, confirming that the neuropathy observed in our hypothyroid patients was length dependent.

Both patients with electroneurographic findings suggesting large fibers neuropathy had also reduced IENF density (Fig. 3).

No significant relationship between IENF density and the thyroid hormonal profile (serum $\mathrm{FT}_{4}$ and serum TSH) or duration of hypothyroidism was found.

\section{Discussion}

Hypothyroidism, particularly when subclinical, is the most common endocrinological disorder, with a prevalence ranging from 4 to $10 \%$ of the adult population $(13,14)$. Hypothyroidism may induce a wide range of neurologic abnormalities. In the past, neurologic complaints were described in up to $80 \%$ of patients with hypothyroidism (15). Most of these patients, having a severe long-standing hypothyroidism, complained of major neurologic symptoms, such as burning and lancinating extremity pain, usually related to a small-fiber damage (6). These major neurologic complaints are nowadays rarely reported, probably due to earlier diagnosis and adequate correction of hypothyroidism with levothyroxine $\left(\mathrm{L}-\mathrm{T}_{4}\right)$.

In neurologically asymptomatic patients with hypothyroidism, abnormalities in nerve conduction studies were found in one (16), but not in another study (7). Recently, a small-fiber dysfunction, as assessed by a screening test such as the quantitative sensory testing, was suspected in some hypothyroid patients, who, in spite of treatment with $\mathrm{L}-\mathrm{T}_{4}$, complained of painful of extremities (17). Skin biopsy with IENF fiber density assessment is more sensitive than clinical examination and quantitative sensory testing in detecting abnormalities in small-nerve fibers, although a consensus reference standard for small-fiber neuropathy is still lacking (18). A reduced IENF density, as assessed by skin biopsy, was recently reported in hypothyroid patients treated with $\mathrm{L}-\mathrm{T}_{4}$, who were at the time of the neurologic evaluation euthyroid, subclinically hypothyroid or even thyrotoxic (19). Thus, the groups of patients included in this study were clinically and biochemically different, and could not be considered as one category (20).

In our series of untreated hypothyroid patients, an asymptomatic polyneuropathy was demonstrated by conventional neurophysiological studies in only two cases $(11.1 \%)$. On the other hand, using the skin biopsy technique, a significant reduction of IENF density was observed in patients with both $\mathrm{OH}$ and SH. The prevalence of individually evaluated abnormal IENF density ranged from $60 \%$ in $\mathrm{OH}$ to $25 \%$ in subclinical thyroid failure. In all affected patients, the IENF density reduction was length dependent. These findings suggest that in hypothyroid patients with no signs or symptoms of nerve damage, neurologic abnormalities can be
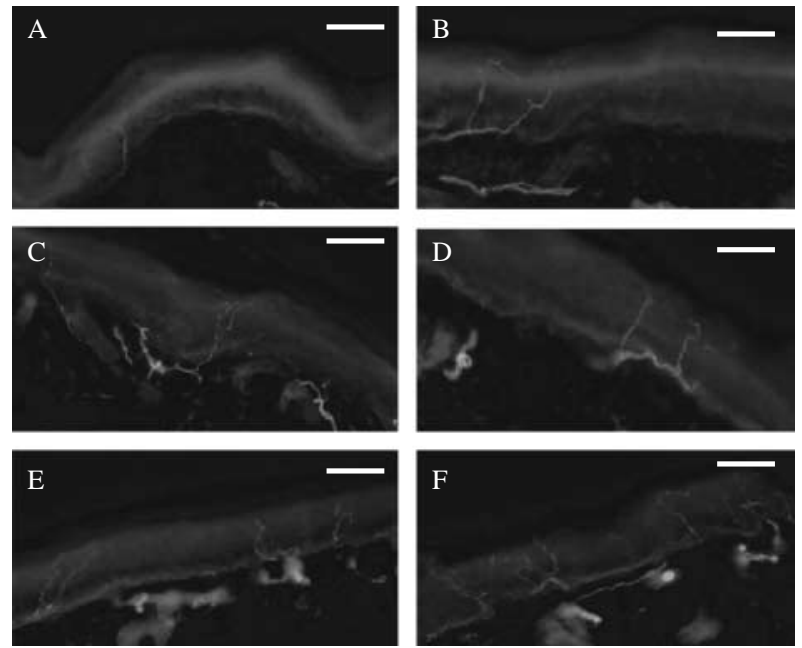

Figure 2 Representative visualization of nerve fibers by indirect immunofluorescence on skin biopsy specimens from patients with overt ( $A$ and $B$ ) and subclinical ( $C$ and $D$ ) hypothyroidism and in normal subject ( $E$ and $F)$. A, C, and $E$ are samples from distal leg, BDF from thigh. Space bar: $50 \mu \mathrm{m}$. 


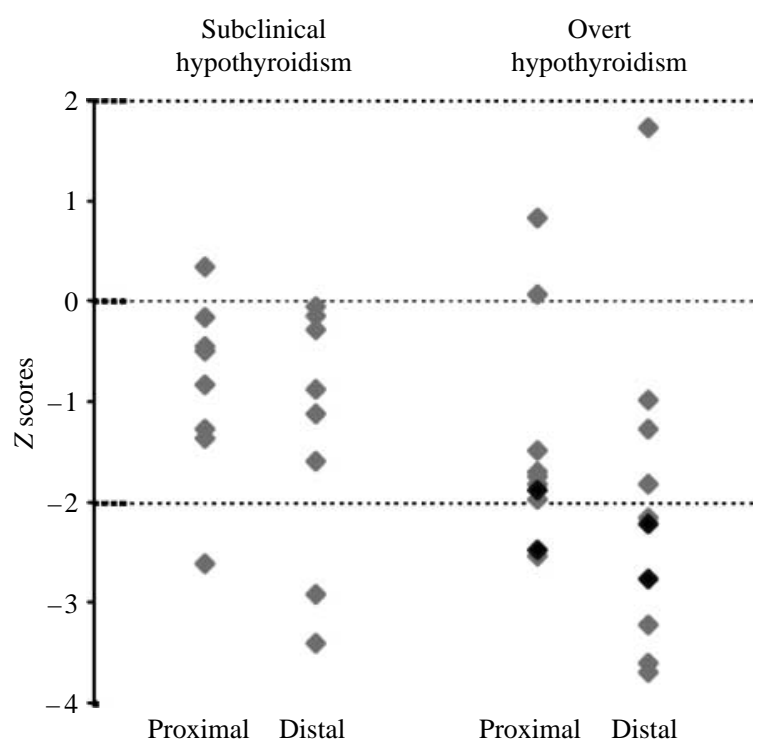

Figure 3 Intraepidermal nerve fiber (IENF) density. A $Z$ score $<2$ indicates a significant reduction in IENF density when patients were considered individually. The IENF results of the two patients with sensory-motor polyneuropathy are indicated in black type, as assessed by conventional neurophysiological study.

detected using the skin biopsy technique. Moreover, preliminary data obtained in a subgroup of our patients indicate that after 1 year on $\mathrm{L}_{-} \mathrm{T}_{4}$ treatment, the nerve fiber density does improve, especially at distal site, in both $\mathrm{OH}$ and $\mathrm{SH}$ (data not shown). The lack of correlation between IENF density and the duration of the hypothyroid state may be due to the small number of studied subjects and to the difficulty in determining the duration of hypothyroidism. The nonsignificant relationship between IENF density and the severity of thyroid failure is in agreement with previous data in the literature showing no direct relation between peripheral and central nervous system alterations and $\mathrm{FT}_{4}$ or $\mathrm{TSH}$ serum concentrations (21).

The relationship between IENF density and pain is still debated. However, there is evidence suggesting that the degree of IENF density loss is related to the severity of the neuropathy (22). On the other hand, in sensory neuropathy, an increase in IENF density is associated with a reduction in neuropathic pain (23). Thus, based on the present results, we can assume that even SH can be considered a potential cause of symptomatic peripheral neuropathy.

The pathophysiological mechanisms leading to SFSN in hypothyroid patients are still unclear. Because in the majority of hypothyroid patients, the cause of thyroid failure was autoimmune thyroiditis, the possible involvement of immune mechanisms in the development of SFSN may be speculatively taken into account. Such an immune neuropathy has been described in patients with systemic lupus erythematosus, Sjögren syndrome, and rheumatoid arthritis (24).
The question of whether $\mathrm{SH}$ should always be treated is a matter of discussion $(25,26)$. Several panels of experts examined this question and reached different conclusions, recommending either in favor or against $\mathrm{L}^{-} \mathrm{T}_{4}$ treatment (27). Our findings, suggesting the presence of a preclinical SFSN not only in $\mathrm{OH}$ but also in $\mathrm{SH}$, although limited to a small number of cases, might represent a further argument favoring the treatment with $\mathrm{L}-\mathrm{T}_{4}$ of patients with subclinical thyroid failure.

\section{Declaration of interest}

The authors declare that there is no conflict of interest that could be perceived as prejudicing the impartiality of the research reported.

\section{Funding}

This research did not receive any specific grant from any funding agency in the public, commercial, or not-for-profit sector.

\section{References}

1 Nemni R, Bottacchi E, Fazio R, Mamoli A, Corbo M, Camerlingo M, Galardi G, Erenbourg L \& Canal N. Polyneuropathy in hypothyroidism: clinical, electrophysiological and morphological findings in four cases. Journal of Neurology, Neurosurgery, and Psychiatry 198750 1454-1460.

2 Beghi E, Delodovici ML, Bogliun G, Crespi V, Paleari F, Gamba P, Capra M \& Zarrelli M. Hypothyroidism and polyneuropathy. Journal of Neurology, Neurosurgery, and Psychiatry 198952 1420-1423.

3 Lin KP, Kwan SY, Chen SY, Chen SS, Yeung KB, Chia LG \& Wu ZA. Generalized neuropathy in Taiwan: an etiologic survey. Neuroepidemiology 199312 257-261.

4 Rudolph T \& Farbu E. Hospital-referred polyneuropathies - causes, prevalences, clinical- and neurophysiological findings. European Journal of Neurology 200714 603-608.

5 Monzani F, Caraccio N, Del Guerra P, Casolaro A \& Ferrannini E. Neuromuscular symptoms and dysfunction in subclinical hypothyroid patients: beneficial effect of $\mathrm{L}-\mathrm{T}_{4}$ replacement therapy. Clinical Endocrinology 199951 237-242.

6 Crevasse LE \& Logue RB. Peripheral neuropathy in myxedema. Annals of Internal Medicine 195950 1433-1437.

7 Somay G, Oflazoğlu B, Us O \& Surardamar A. Neuromuscular status of thyroid diseases: a prospective clinical and electrodiagnostic study. Electromyography and Clinical Neurophysiology $20074767-78$.

8 Penza P, Lombardi R, Camozzi F, Ciano C \& Lauria G. Painful neuropathy in subclinical hypothyroidism: clinical and neuropathological recovery after hormone replacement therapy. Neurological Sciences 200930 149-151.

9 Devigili G, Tugnoli V, Penza P, Camozzi F, Lombardi R, Melli G, Broglio L, Granieri E \& Lauria G. The diagnostic criteria for small fiber neuropathy: from symptoms to neuropathology. Brain 2008 131 1912-1925.

10 England JD, Gronseth GS, Franklin G, Carter GT, Kinsella LJ, Cohen JA, Asbury AK, Szigeti K, Lupski JR, Latov N, Lewis RA, Low PA, Fisher MA, Herrmann DN, Howard JF Jr, Lauria G, Miller RG, Polydefkis M, Sumner AJ \& American Academy of Neurology. Practice parameter: evaluation of distal symmetric polyneuropathy: role of autonomic testing, nerve biopsy, and skin biopsy (an evidence-based review). Report of the American 
Academy of Neurology, American Association of Neuromuscular and Electrodiagnostic Medicine, and American Academy of Physical Medicine and Rehabilitation. Neurology 200972 177-184.

11 American Diabetes Association. Diagnosis and classification of diabetes mellitus. Diabetes Care 200932 S62-S67.

12 Lauria G, Cornblath DR, Johansson O, McArthur JC, Mellgren SI, Nolano M, Rosenberg N, Sommer C \& European Federation of Neurological Societies. EFNS guidelines on the use of skin biopsy in the diagnosis of peripheral neuropathy. European Journal of Neurology 200512 747-758.

13 Hollowell JG, Staehling NW, Flanders WD, Hannon WH, Gunter EW, Spencer CA \& Braverman LE. Serum TSH, T(4), and thyroid antibodies in the United States population (1988 to 1994): National Health and Nutrition Examination Survey (NHANES III). Journal of Clinical Endocrinology and Metabolism 2002 87 489-499.

14 Canaris GJ, Manowitz NR, Mayor G \& Ridgway EC. The Colorado thyroid disease prevalence study. Archives of Internal Medicine 2000 $160526-534$.

15 Duyff RF, Van den Bosch J, Laman DM, van Loon BJ \& Linssen WH. Neuromuscular findings in thyroid dysfunction: a prospective clinical and electrodiagnostic study. Journal of Neurology, Neurosurgery, and Psychiatry 200068 750-755.

16 El-Salem K \& Ammari F. Neurophysiological changes in neurologically asymptomatic hypothyroid patients: a prospective cohort study. Journal of Clinical Neurophysiology 200623 568-572.

17 Ørstavik K, Norheim I \& Jørum E. Pain and small-fiber neuropathy in patients with hypothyroidism. Neurology $2006 \mathbf{6 7} 786-791$.

18 Hlubocky A, Wellik K, Ross MA, Smith BE, Hoffman-Snyder C, Demaerschalk BM \& Wingerchuk DM. Skin biopsy for diagnosis of small fiber neuropathy: a critically appraised topic. Neurologist 201016 61-63.
19 Nebuchennykh M, Løseth S \& Mellgren SI. Aspects of peripheral nerve involvement in patients with treated hypothyroidism. European Journal of Neurology 201017 67-72.

20 Magri F, Oliviero A, Rotondi M \& Chiovato L. Comments on 'aspects of peripheral nerve involvement in patients with treated hypothyroidism'. European Journal of Neurology 201017 e13.

21 Khedr EM, El Toony LF, Tarkhan MN \& Abdella G. Peripheral and central nervous system alterations in hypothyroidism: electrophysiological findings. Neuropsychobiology 200041 88-94.

22 Sommer C \& Lauria G. Skin biopsy in the management of peripheral neuropathy. Lancet Neurology 20076 632-642.

23 Nodera H, Barbano RL, Henderson D \& Herrmann DN. Epidermal reinnervation concomitant with symptomatic improvement in a sensory neuropathy. Muscle \& Nerve 200327 507-509.

24 Gøransson LG, Herigstad A, Tjensvoll AB, Harboe E, Mellgren SI \& Omdal R. Peripheral neuropathy in primary Sjogren syndrome: a population-based study. Archives of Neurology $2006 \mathbf{6 3}$ 1612-1615.

25 Ringel MD \& Mazzaferri EL. Subclinical thyroid dysfunction - can there be a consensus about the consensus? Journal of Clinical Endocrinology and Metabolism 200590 588-590.

26 Cooper DS. Subclinical thyroid disease: consensus or conundrum? Clinical Endocrinology $200460410-412$.

27 Biondi B \& Cooper DS. The clinical significance of subclinical thyroid dysfunction. Endocrine Reviews 200829 76-131.

Received 6 May 2010

Accepted 11 May 2010 